\title{
Assessment of beef cattle fattening practices and its challenges in and around Mekelle, Tigray, Ethiopia
}

\author{
Teklehaymanot Gebremichael ${ }^{1,}$ Tsegay Tkue Gebrewahd ${ }^{1^{*}}$ and Niraj Kumar ${ }^{1}$ \\ ${ }^{1}$ College of Veterinary Medicine, Mekelle University, P.O.Box: 2080, Mekelle, Ethiopia \\ *Corresponding author: Tsegay Tkue Gebrewahd, Email: tsegay1984t@gmail.com \\ https://dx.doi.org/10.4314/evj.v21i1.3
}

\begin{abstract}
A cross sectional study was conducted from April to June, 2016 with the objective of assessing the beef cattle fattening practices and its challenges in and around Mekelle. Accordingly, data was collected from all $(\mathrm{N}=108)$ beef cattle fatteners in the study area, by face-to-face interview using a pretested structured and semi-structured questionnaires. Moreover, participatory group focused discussion and personal observation were among the tools used to collect relevant data for this study. Based on the results of the current study, all of the interviewed farmers use male animals for fattening purpose. The farmers use different criteria to select the best animals to be fattened, and age, body size and body condition status of the animals are among the major ones. Regarding the housing condition of the animals to be fattened, $61.1 \%$ of the fattening houses had complete roof and side walls to protect the animals from predators and being exposed to rain and sun light. On the other hand, $38.9 \%$ of the fattening houses were constructed without roof, but fenced with different locally available fencing materials, such as wood, thorny plants and stones. Almost all $(97.2 \%)$ of the fattening houses' floors were soil type without drainage system. The beef cattle fattening in the study area is challenged by different constraints, such as shortage of feed (100\%), shortage of land $(78.7 \%)$, market problem $(75.9 \%)$, and diseases $(58.3 \%)$. Therefore, it is very important to solve these constraints to enhance production and productivity of the beef cattle, and thereby improve the livelihood of the farmers in the study area.
\end{abstract}

Keywords: Beef cattle; Challenges; Fattening; Mekelle

\section{Introduction}

Ethiopia has the largest livestock population in Africa, comprising, cattle: 56.71 million, sheep: 29.33 million, and goats: 29.11 million (CSA, 2014/2015). The 
greatest concentration occurs in the highlands, where $70 \%$ of the human populations live. Livestock and livestock products contribute $35 \%$ of the agriculture output and additionally supply the power to cultivate. Virtually Ethiopian's entire 6 million have land cropped annually. Exports of livestock products are presently limited to hides and skins but a great potential exists and maximum efforts is being exerted for exports of beef mutton and live animals, especially to the middle east countries. In Ethiopia, livestock is the second largest earner of foreign exchange after coffee (Mulugeta Bekele et al., 2005).

Recent studies indicated the higher economic, social, and environmental importance of livestock to local and the national economy. However, the significance of sustainable livestock management, its economic, social and environmental benefits continue to be under addressed by policy and decision makers in favor of crop based agricultural expansion and other land use (EEA, 2005). The use of agro-industrial by products as animal feed has been a common practice for many years in industrialized nations where millions of tonnes are produced each year. This development has been as the result of intensified activities designed to find efficient methods of recycling agricultural wastes (Chaturevedi et al., 1984).

In Ethiopia, crop residues, cereal straws, pulses and other crops are the main sources of roughage for small -scale and commercial fatteners operating around farming areas and cereals straws from teff (Eragrostis teff), barley (Hordeum vulgare), and wheat (Triticum) are the largest component of the livestock diets. The residues are stacked after threshing and fed during the dry season. Forage represents a diverse range of feed stuffs that make a significance contribution to the overall nutritional economy of meat producing ruminants. However, it is this diversity which presents both opportunities and challenges when attempting to exploit these feeds. A cost effective efficacious herd and production management program is essential for the economic viability of most beef cattle production. What such program entails, however, varies with region, relative economics, perceptions, and opportunity (Kelly and Janzen, 1996).

Throughout the world a great variation exists in beef cattle fattening operations in terms of management, environmental setting degree of intensification, type of cattle used, productivity, and profitability (Radostits, 2001). Despite many studies that have been conducted on beef cattle fattening practices and its challenges in the different districts of the country, there is a study gap in 
and around Mekelle. Therefore, this study was conducted to assess the beef cattle fattening practices and its challenges in the study area.

\section{Materials and Methods}

\section{Description of the study area}

The study was conducted in and around Mekelle, which is the capital city of Tigray regional state. Mekelle is located at an altitude which ranges from 17002100 meter above sea level (masl), latitude $13^{\circ} 29^{\prime} 33.6^{\prime \prime}$ North, and longitude $39^{\circ} 28^{\prime} 44.99^{\prime \prime}$ East. It shares common boundaries with its neighboring Weredas north with Wukro, south Hintalo Wajirat, east Afar and west with Deguatemben. The total area of the wereda is estimated to be approximately 888055 ha. In the wereda a mixed crop-livestock production system is dominant, and it significantly contributes for the livelihood of the farmers. The major crops grown in the study area are: teff, barley, wheat, sorghum, and maize.

\section{Data collection and sampling technique}

A cross sectional study was conducted to collect data on beef cattle fattening practices and its challenges in and around Mekelle. First, structured and semi-structured questionnaires were developed, and translated to the local language for ease of understanding by the respondents. Then, a pilot study was conducted on some of the respondents to get relevant information for the development of the final questionnaire. Next, the final questionnaires were designed by incorporating the relevant information obtained from the pilot study. Since the farmers in the study area who were involved in beef cattle fattening were very few in number $(\mathrm{N}=108)$, data was collected from all of them by face-to-face interview. The farmers were asked questions such as their farming experience, housing and feeding managements of beef cattle, record keeping, and major constraints for beef cattle fattening in the study area. Moreover, participatory group focused discussion and personal observations were among the tools used to collect relevant data for the study.

\section{Data analysis}

The collected raw data was entered into an Excel sheet, cleaned, coded, imported and analyzed using a Statistical Package for Social Sciences (SPSS) version 20. Then, descriptive statistical analysis such as frequency and percentages were calculated for the qualitative data. Moreover, a Chi-Square test ( $\mathrm{X}^{2}$-test)

Ethiop. Vet. J., 2016, 21 (1), 29-39 
was conducted to see any association among some parameters, and a P-value $<0.05$ was considered statistically significant association.

\section{Results}

\section{Respondents' biography and socioeconomic characteristics}

According to the results of the current study, $96.3 \%$ of the respondents were males, and $32.4 \%$ of them were at the elementary level of education, Majority of the respondents (63.9\%), were livestock producers only, whereas $36.1 \%$ of them were mixed crop livestock producers (Table 1).

Table 1. Respondents' biography and socioeconomic characteristics

\begin{tabular}{llcc}
\hline Variables & categories & frequency & Percent (\%) \\
\hline Sex & Male & 104 & 96.3 \\
& Female & 4 & 3.7 \\
Level of education & Illiterate & 19 & 17.6 \\
& Basic education & 24 & 22.6 \\
& Elementary & 35 & 32.4 \\
& Secondary & 24 & 22.2 \\
& Certificate & 1 & 9 \\
& Diploma and above & 5 & 4.6 \\
& Livestock production & 69 & 63.9 \\
& Crop production & 1 & 9 \\
& Mixed crop livestock production & 38 & 35.2 \\
\hline
\end{tabular}

\section{Selection and marketing of beef cattle}

Based on the results of the current study, all of the interviewed farmers use local breed of male animals, and $57.4 \%$ of them use medium age animals (3-4 years) for fattening purpose. Regarding the source of the animals used for fattening, $84.3 \%$ of them are purchased from local farmers. Moreover, all of the interviewed farmers buy and sell animals by visual judging (Table 2). This implies, the livestock marketing system in the study area is traditional. 
Table 2. Selection and marketing of beef cattle

\begin{tabular}{llcc}
\hline Variables & Categories & Frequency & Percent (\%) \\
\hline Sex of animals used for fattening & Male & 108 & 100 \\
& Female & 0 & 0 \\
Breed of animals used for fattening & Local & 93 & 86.1 \\
& Crosse & 15 & 13.9 \\
Age of animals used for fattening & Young (1-2 years) & 0 & 0 \\
& Medium (3-4 years) & 62 & 57.4 \\
& Old (over 4 years) & 46 & 42.6 \\
Sources of animals used for fattening & Local farmers & 91 & 84.3 \\
& Brokers & 17 & 15.7 \\
Customers for selling fattened animals & Local butchery houses & 42 & 38.9 \\
\hline
\end{tabular}

It is also found that, age, body condition score and body size of the animals to be fattened are used as selection criteria by majority $(89 \%)$ of the farmers (Figure 1).

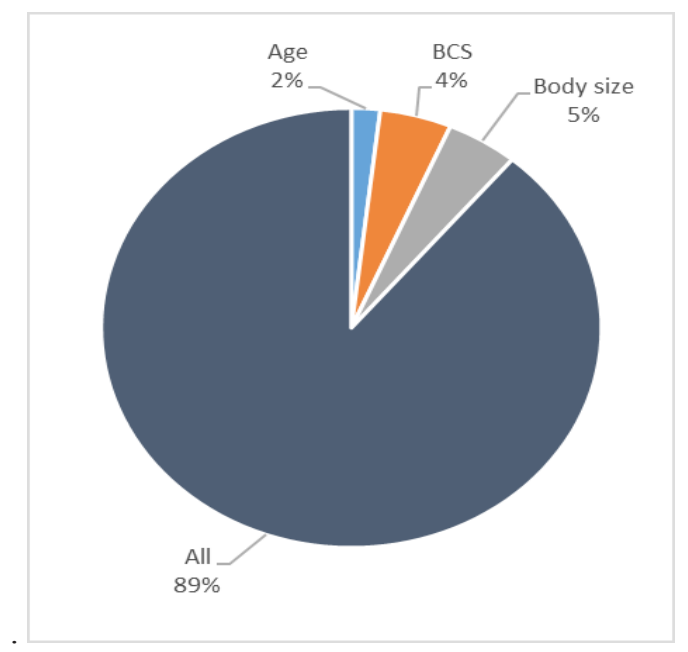

Figure 1. Criteria used to select animals for fattening 


\section{Housing managements of fattening animals}

Regarding the housing managements of animals used for fattening purpose, $61.1 \%$ of the farmers keep their animals in fattening houses with complete roof and wall, whereas the rest of them use fattening houses with no roof and complete wall, but fenced using locally available materials, like thorny plants and others. The result of the current study revealed that, $66.7 \%$ of the farmers did not get professional advice before constructing the fattening houses, thereby, $57.4 \%$ of them do not know the space requirement per animal (Table 3). This implies, the extension service in the study area to farmers involved in beef cattle fattening is very low.

Table 3. Housing managements of fattening animals

\begin{tabular}{|c|c|c|c|}
\hline Variables & Categories & Frequency & Percent (\%) \\
\hline \multirow[t]{2}{*}{ Type of fattening house } & enclosure or kraal & 42 & 38.9 \\
\hline & $\begin{array}{l}\text { With roof and complete } \\
\text { wall }\end{array}$ & 66 & 61.1 \\
\hline \multirow{2}{*}{$\begin{array}{l}\text { Do you consult professionals } \\
\text { before constructing the house for } \\
\text { fattening? }\end{array}$} & Yes & 36 & 33.3 \\
\hline & No & 72 & 66.7 \\
\hline \multirow[t]{2}{*}{ Floor type of the fattening house } & Cement & 3 & 2.8 \\
\hline & Soil & 105 & 97.2 \\
\hline \multirow{2}{*}{$\begin{array}{l}\text { Availability of drainage system in } \\
\text { fattening house }\end{array}$} & Available & 88 & 81.5 \\
\hline & Unavailable & 20 & 18.5 \\
\hline \multirow{2}{*}{$\begin{array}{l}\text { Do you use a bedding material for } \\
\text { the floor? }\end{array}$} & Yes & 45 & 41.7 \\
\hline & No & 63 & 58.3 \\
\hline $\begin{array}{l}\text { What type of bedding material do } \\
\text { you use? }\end{array}$ & Sand & 48 & 44.4 \\
\hline \multirow{2}{*}{$\begin{array}{l}\text { Do you know the space requiremt/ } \\
\text { animal? }\end{array}$} & Yes & 46 & 42.6 \\
\hline & No & 62 & 57.4 \\
\hline
\end{tabular}

\section{Feeding management of fattening animals}

This study revealed that, $76.9 \%$ of the farmers use exclusively intensive farming. Moreover, the farmers use roughage and concentrate feeds to fatten their animals, and grains and wheat bran are among the concentrate feeds which are commonly used (Table 4). 
Table 4. Feeding management of fattening animals

\begin{tabular}{|c|c|c|c|}
\hline Variables & Categories & Frequency & Percent (\%) \\
\hline \multirow[t]{3}{*}{ Feeding system } & Intensive & 83 & 76.9 \\
\hline & Semi intensive & 25 & 23.1 \\
\hline & Extensive & 0 & 0 \\
\hline \multirow[t]{2}{*}{ Type of feeds used for fattening } & Concentrate & 70 & 64.8 \\
\hline & Roughage & 38 & 35.2 \\
\hline \multirow[t]{3}{*}{ Type of concentrate feeds } & Grains & 15 & 13.9 \\
\hline & Wheat bran & 35 & 32.4 \\
\hline & Others & 29 & 26.9 \\
\hline \multirow{2}{*}{$\begin{array}{l}\text { Do you know the mount of } \\
\text { concentrate feeds in Kg/animal/ } \\
\text { day? }\end{array}$} & Yes & 18 & 16.7 \\
\hline & No & 90 & 83.3 \\
\hline \multirow{3}{*}{$\begin{array}{l}\text { What type of roughage feeds do } \\
\text { you use? }\end{array}$} & Straw & 79 & 73.1 \\
\hline & Hay & 17 & 15.7 \\
\hline & Others & 12 & 11.1 \\
\hline \multirow{2}{*}{$\begin{array}{l}\text { How do you fed the fattening } \\
\text { animals? }\end{array}$} & Individually & 35 & 32.4 \\
\hline & In group & 73 & 67.6 \\
\hline
\end{tabular}

\section{Association between some parameters}

In this study, a Chi-square test was computed to see if there is any association between the farmers' level of education and their preference to the age of animals used for fattening purpose. Hence, it is found that, there was a statistically significant association $\left(\mathrm{X}^{2}=21.488, \mathrm{p}=0.001\right)$, between the farmers' level of education and their preference for the age of animals used for fattening purpose. Accordingly, farmers who are illiterate and that have a basic education prefer animals in the old age group (over 4 years), whereas, farmers in the elementary and above level of education prefer animals in the medium age group (3-4 year). This implies, as the farmers' level of education increases, their preference to animals in the old age group decreases too (Table 5). According to the informal communication with the farmers, meat from old animals is very tough, and less palatable. 
Table 5. Association between respondents level of education and age of animals used for fattening

\begin{tabular}{|c|c|c|c|c|c|}
\hline \multirow{2}{*}{$\begin{array}{l}\text { Variable } \\
\text { Level of education }\end{array}$} & \multirow[t]{2}{*}{ Category } & \multicolumn{2}{|c|}{$\begin{array}{l}\text { Age of animals used for } \\
\text { fattening }\end{array}$} & \multirow[t]{2}{*}{$\mathrm{X}^{2}$} & \multirow[t]{2}{*}{ P-value } \\
\hline & & $\begin{array}{l}\text { Medium }(3-4 \\
\text { years })\end{array}$ & $\begin{array}{l}\text { Old (over } 4 \\
\text { years) }\end{array}$ & & \\
\hline & Illiterate & $5(8.1 \%)$ & $14(30.4 \%)$ & \multirow[t]{6}{*}{21.488} & \multirow[t]{6}{*}{0.001} \\
\hline & Basic education & $9(14.5 \%)$ & $15(32.6 \%)$ & & \\
\hline & Elementary & $23(37.1 \%)$ & $12(26.1 \%)$ & & \\
\hline & Secondary & $19(30.6 \%)$ & $5(10.9 \%)$ & & \\
\hline & Certificate & $1(1.6 \%)$ & $0(0.00 \%)$ & & \\
\hline & $\begin{array}{l}\text { Diploma and } \\
\text { above }\end{array}$ & $5(8.1 \%)$ & $0(0.00 \%)$ & & \\
\hline
\end{tabular}

\section{Constraints for beef cattle fattening}

Based on the results of the current study, there are many constraints affecting beef cattle fattening in the study area. All of the interviewed farmers complained, they have shortage of animal feeds, especially concentrates. This affects the production and productivity of the fattening animals, and livelihood of the farmers (Figure 2).

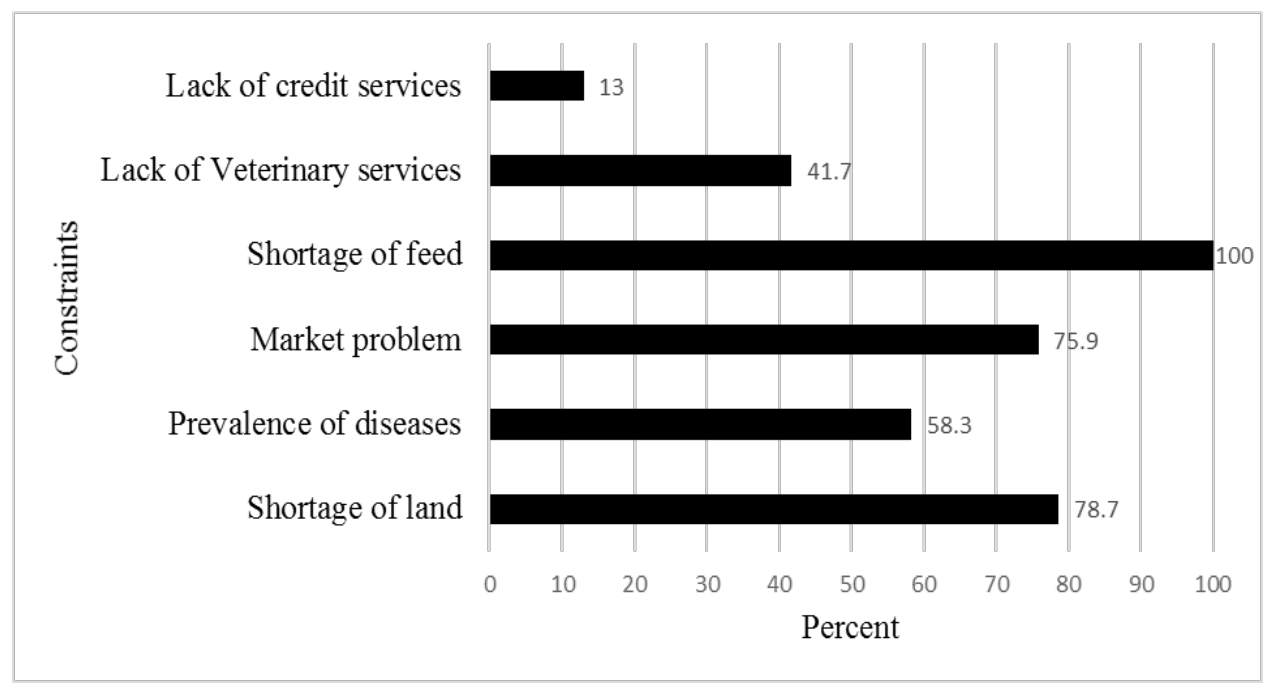

Figure 2. Constraints for beef cattle fattening in the study area 


\section{Discussion}

Results of the current study revealed that, $63.9 \%$ of the farmers were exclusively livestock producers, whereas the rest were mixed crop livestock producers. The reason why most of the farmers keep exclusively livestock could be due shortage of land for crop production, since the farmers are from the urban and peri-urban areas, where urbanization is growing rapidly. Moreover, the high demand of the urban and peri-urban people for meat could encourage the farmers to focus on livestock, mainly beef cattle production. Age, sex, body condition score, body size and breed of the animals to be fattened were used as selection criteria. For instance, based on the results of the current study, medium age (3-4 years old) and of local breed animals were highly preferred for fattening purpose. According to the informal communication with the farmers, this is due to availability, high disease resistance, and low feed intake capacity of the local breed animals. Moreover, due to the poor quality, such as palatability and toughness of meat from old animals, majority of the farmers need animals to be fattened in the medium age group (3-4 years). Framers' tendency of using different criteria to select the best animals for fattening is also supported by Takele Taye and Habtamu Lemma (2009), who reported fatteners in Welaita and northern part of Ethiopia select fattening cattle of tall height, good body condition and big and stand-high hump, in addition to coat color and sex. According to the informal communication with some of the farmers, they prefer animals with medium, and sometimes poor body condition. This could be due to the fact that, animals with medium or poor body condition are cheaper than animals with good body condition, and they can quickly compensate their growth.

According to the findings of the present study, the most available feeds in the area were industrial byproducts (concentrates) with expensive purchasing prices, and there were no other green feeds. The average fattening duration was three months, and this differs from the results of Takele Taye and Habtamu Lemma (2009), who reported cattle feeders fed cattle usually for four months in Welaita area of southern Ethiopia and Bahrdar area of northern Ethiopia. The variation in the duration of fattening among these different study areas may be due to the high cost and unsustainable availability of concentrate feeds in the current study area, thereby the farmers can not be profitable in their business. Moreover, energy content of the feed, market availability, purchasing body weight, and intended body weight of the animals and others can determine the duration in which fattening animals are kept in a feedlot. Based on the findings of the current study, there are many constraints for beef cattle

Ethiop. Vet. J., 2016, 21 (1), 29-39 
fattening in the study area, and all of the farmers complained, feed shortage as the major constraint affecting the production and productivity of the fattening animals, and livelihood of the farmers. This result is in line with the results of Gezu Tadesse (2014), who reported, farmers involved in beef cattle fattening in Lemo and Sero weredas, complained, shortage of feed to be among the major constraints for beef cattle fattening.

Lack of market to sell fattened animals was also a constraint for beef cattle fattening, and this could be due to unorganized marketing system, and unplanned fattening periods such as being dependent on cultural holidays and season. In the present study area, 58.3\% of the farmers complained, there are many diseases affecting the production and productivity of the fattening animals. This result is similarly interpreted with the findings of Gebregziabher Gebreyohannes and Gebrehiwot Hailemariam (2011), who reported 54.6\% of the farmers complained diseases as the major constraints for beef cattle fattening in Tigray and Hararghe. Despite the presence of many constraints for beef cattle fattening in the study area, there are also some opportunities which encourage the farmers. This is justified by the fact that most of the farmers did not complain for shortage of credit services. This result is not in agreement with the report of Anteneh Belete et al. (2010) who reported, lack of credit service was the first constraint to the cattle fattening in Fogora wereda, Amhara region. Therefore, it is highly important to solve the existing constraints affecting beef cattle production and productivity in the study area, thereby improve the livelihood of the farmers in particular and the region in general.

\section{Acknowledgements}

The authors would like to thank for the farmers and responsible offices of the study area, for their considerable cooperation during the data collection process.

\section{References}

Bekele M., B., Girma, A. and Solomon, L., 2005. Urban cattle fattening system. Debub University, Animal and Range Sciences, Ethiopia.

Belete, A., Azage, T., Fekadu, B. and Berhanu, G., 2010. Cattle milk and meat production and marketing systems and opportunity for market orientation in Fogera wereda, Amhara region, Ethiopia. 
Chaturevedi, M.L., Signa, U. B. and Ronihan, S.K., 1984. Effect of water soaked and dry Wheat straw on feed intake. Agri. Sci., 80, 393-394.

CSA (Central Statistical Agency), 2014/2015. Agricultural Sample Survey. Report on Livestock and Livestock Characteristics, Volume II, Federal Democratic Republic Of Ethiopia.

EEA (Ethiopian Economics Association), 2005. Conference on feed resources for livestock Addis Abeba, Ethiopia.

Gebreyohannes G, and Hailemariam G., 2011. Challenges, opportunities and available good practice related to zero grazing in Tigray and Hararghe, Ethiopia, DCG report No.66.

Kelly, A. P. and Janzen, E.D., 1996. A review of Morbidity and mortality rates and disease occurrence in north American feed lot cattle. Can.Vet.J., 27, 496-500.

Radostits, O.M., 2001. Herd Health, Food Animal Production Medicine, 3rd ed W.B Saunders Company.

Tadesse, G., 2014. Food resource and constraints for cattle fattening in Lemo and Sero wereda.Wochemo Univesty, Hosana, Ethiopia.

Taye T. and Lemma, H., 2009. Traditional backyard cattle fattening in Welyta: System of operation and routine husbandry practice. Ethiop. J. Anim. Prod., 9 (1), 39-56. 